\title{
Clavicle Fracture
}

National Cancer Institute

\section{Source}

National Cancer Institute. Clavicle Fracture. NCI Thesaurus. Code C26987.

A traumatic or pathologic injury to the clavicle in which the continuity of the clavicle is broken. 